\title{
SAPERE AUDE (DIZIA KANT): A BIBLIOGRAFIA, UMA ORDEM DO DISCURSO DO SÉCULO XXI?
}

\author{
SAPERE AUDE (DECÍA KANT): LA BIBLIOGRAFÍA, UNA \\ ORDEN DEL DISCURSO DEL SIGLO XXI?
}

Attilio Mauro Caproni²

\begin{abstract}
RESUMO
Introdução: a reflexão histórica e teórica coloca em questão a condição da Bibliografia no século XX, considerada como o grande século dos livros, a partir do pensamento bibliográfico italiano. Objetivos: discutir o lugar da Bibliografia no século XX e seus determinantes sócio-históricos. Metodologia: a partir de natureza bibliográfica, o estudo constituiu-se como um trabalho histórico, de fundo teórico, tendo como argumento o discurso de Kant, guiado pela máxima "tenha a coragem de saber". Resultados e conclusões: a reflexão nos leva a uma discussão sobre a Bibliografia, o livro e as transformações das redes sociais digitais contemporâneas, explicando as contradições da interpretação de tais fenômenos no tempo histórico e demarcando a Bibliografia como uma memória da escrita e o livro como uma espécie de entidade absoluta.
\end{abstract}

Descritores: Bibliografia - Século XX. Conhecimento. Livro. Redes sociais. Web.

\footnotetext{
${ }^{1}$ N.T.: Tradução do italiano para o português por Giulia Crippa (USP). Revisão da tradução e notas da tradução por Andre Vieira de Freitas Araujo (UFRJ).

2 N.T. Professor Titular de Bibliografia na Università degli Studi di Udine, onde ocupou o cargo de Diretor da Faculdade de Letras e Filosofia e Diretor do Instituto de História. Na mesma Universidade, ele fundou, e dirigiu, o Doutorado em Ciências Bibliográficas, do XVI ao XXV Ciclo. Atualmente é responsável pelo ensino de Bibliografia na Università degli Studi di Firenze. Fundou e dirigiu (diretor científico) a Revista Bibliotheca (com Alfredo Serrai como diretor responsável). É diretor de coletâneas editoriais sobre os temas bibliográficos. Participa de comitês científicos de revistas italianas. Os seus estudos, depois de um primeiro enfoque sobre argumentos biblioteconômicos, e sobre tipografia de vanguarda histórica, destacaram o estudo de bibliotecas privadas e, sobretudo, sobre temas de teoria da Bibliografia, com alguns significativos livros: A inquietude do saber, Pensamentos dentro das palavras, O labirinto da inteligência, além de outros ensaios, artigos e textos. Possui em preparação uma coletânea de ensaios de argumento bibliográfico.
} 
[...] La verità è solo negli oggetti, come l'oggettività è nella verità. (Walter Benjamin)

Cedo ou tarde precisaremos nos perguntar, ultrapassado o milênio que está atrás de nós, e já passados dezessete anos desde aquele fatídico 31 de dezembro de 1999, qual é a relação entre a Bibliografia e o século XX e tentar, em primeiro lugar, entender, no lugar de um balanço aproximativo, quanto daquele tempo ainda é parte para muitos (ou talvez poucos) de nós? Assim, no século XXI, por outro lado, uma porção consistente daquela análise ainda existe, ou já se encontra uma outra perspectiva: isto é, uma visão periscópica além dos muros do século breve, com seus mitos, ou as catástrofes constantes, fórmulas ou hábitos?

É necessário (logo) um esclarecimento, apto - esperamos - a afugentar equívocos e a desviar desentendimentos: termos de comparação é, aqui, o grande século XX dos livros (de Georg Schneider a Ernest Daniel Grand, Henri Stein (final de 1800), Charles - Victor Langlois; da Friédrick Johann Kleemeier a Louise Noëlle Malclès; da Arundell Esdaile, Roy Stokes a Wilhem Totok, até alcançar os estudos recentes, não alcançáveis, por sua fundamental importância, do sumo Alfredo Serrai (e sem, todavia, esquecer, no âmbito italiano, os textos relevantes de Luigi Ferrari, Giuseppe Fumagalli e, em anos mais próximos, de Piero Innocenti, Luigi Balsamo, Fiammetta Sabba e, se me é humildemente permitido, minha modesta e plurianual contribuição teórica, somente para citar alguns nomes - e não outras categorias possíveis, só aparentemente parecidas). Então, de forma muito intuitiva, e sem recorrer a paramentos teóricos pletóricos, e sem esmiuçar aquele século lembrado em partículas temporais, e utilizando, pelo contrário, uma noção ampla e livre do período, pense-se aqui, por assim dizer, em termos molares. Ou seja, para simples utilidade demonstrativa, como a um reticulado compacto cujos elementos são bem perceptíveis na consciência interpretativa comum. Em outros termos: há algo em comum - além dos traços específicos de cada um - 
entre o livro em papel e/ou o file, ou entre a tipografia e a tecnologia digital? Quais relações a Bibliografia mantém com este sistema de dados compartilhados geral e genérico do século XX de livros (e documentário), com a sociedade da informação do século XXI? Como adere a cultura tipográfica a esta chocante revolução que leva à afirmação do digital? E, ainda, como, em alguns casos, se separa dela tomando um rumo que conduz, através de uma formula abstrata, a lugares não jurisdicionais?

A história da tradição do saber que a cultura registrada se esforça de transmitir tem, na ciência bibliográfica, uma expressão consistente que, no século que agora nos antecede, relacionou dita disciplina no contexto da arqueologia do saber, assim como Michel Foucault fala naquele seu celebrado texto, de 1966, que é intitulado: Les mots et les choses'.

Acontece, com efeito, que um escrito, um vestígio do signo, um fragmento do pensamento que vão constituir uma entidade assim dita libraria ${ }^{2}$, são, obviamente, estes - escrevia em um meu ensaio precedente e recente ${ }^{3}$ elementos fundantes na ciência lembrada. Os vestígios citados, os fragmentos singulares não devem aparecer como os momentos de um discurso incompleto mas, pelo contrário, eles se manifestam como aquela linguagem, e aquela escrita de aparecimento destinados a desenhar um nível da afirmação da inteligência, a qual (provavelmente) está pronta a desemaranhar um determinado enigma do conhecimento.

A ordem e a sistematização do saber escrito que a primeira ciência do livro, hoje, propõe é dirigida por questões primárias:

\footnotetext{
${ }_{1}^{1}$ FOUCAULT, Michel. Les mots et les choses. Paris: Gallimard, 1966.

2 N.T. : O termo libraria/librario, de acordo com Araújo [tradutora] (2014, p. 208), significa " 'relativo aos livros', 'de livros', 'próprio dos livros', 'que se relaciona com o livro'. [...] está também relacionado ao local onde o livro era produzido (taller librario) e às práticas e às técnicas que o materializam. Pode referir-se, ainda, ao local de guarda dos livros - a biblioteca". Cf. RUIZ GARCIA, Elisa. Tipologia do livro. Tradução de Diná Marques Pereira Araújo. Cadernos de História, Belo Horizonte, v. 15, n. 23, p. 208-228, out. 2014. ISSN 2237-8871. Disponível em: <http://periodicos.pucminas.br/index.php/cadernoshistoria/article/viewFile/P.22378871.2014v15n23p208/7221>. Acesso em: 15 jun. 2018.

3 CAPRONI, Attilio Mauro. La Bibliografia nel XXI secolo: una riflessione. In: MISCELLANEA di studi per Anna Giulia Cavagna [título provisório]. Bologna: Patron editore. No prelo.
} 
1. a cultura oferecida por textos não teria ficado sempre em risco se não houvesse a tradição da Bibliografia, que é voltada para a preservação e para transitar, no tempo, o conhecimento do conhecimento?

2. há, também, um saber a não ser sabido?

3. o que é o saber dos livros?

O velho Immanuel Kant, em se perguntar acerca do tema do conhecimento, dizia que a razão e o intelecto dos homens (e dos escritores) podem ser resumidos em um único imperativo intelectual: "sapere aude", isto é: tenha a coragem de saber, de conhecer, de usar a inteligência. Qual outro papel, ou qual outro dever, ou finalidade pública, poderá ser confiada a cada um de nós, aos escritores, aos estudiosos, às diversas obras, à Bibliografia principalmente (à biblioteca, sem dúvida), a não ser aquele dos bons, talvez, tardios iluministas atuais, conscientes, por exemplo, de que a memória que preserva a cultura do signo (tanto em uma forma tipográfica, como de maneira digital) é a única religião possível da humanidade moderna, sem dogmas e sem tutelas. Hoje, de fato, a memorização dos vários textos (vale dizer, a Bibliografia) ainda é um valor fundante da sociedade civil? Esta é, obviamente, uma pergunta pleonástica. De fato, é notório que a transmissão das múltiplas unidades livrescas e/ou documentárias, em suas formas indiciais da nossa disciplina, a mesma transmissão não seria (não é) nada mais que uma transposição da cultura de uma sociedade: transposição, com efeito, que é de fato uma interpretação desta última. Assim, na passagem (por sorte ainda devagar) da tipografia para a tecnologia digital, esta afirmação ainda faz sentido? A última parte do século $X X$ e, acima de tudo, os anos atuais viram o nascimento e o progresso das redes informáticas (internet, principalmente) as quais, mesmo com suas inegáveis possibilidades e qualidades, através de algoritmos exatos, estas redes, por exemplo, se dotaram de múltiplos social networks (mas alguns deles aparentam ter os estigmas de fazer emergir a bêtise ${ }^{4}$ de uma parte relevante de quem as frequenta). Assim, ao lado de uma mudança dessa natureza, a forma do livro está sofrendo, como é evidente, uma

\footnotetext{
${ }^{4}$ N. T: Estupidez.
}

Inf. Inf., Londrina, v. 23, n. 2, p. 04 - 13, maio/ago. 2018. http://www.uel.br/revistas/informacao/ 
sua modificação (e englobamento) na tecnologia digital. E a tecnologia digital, come é sabido (eu aprecio, todavia, seus espaços, diga-se de passagem) é um meio que, para a maioria (os incultos, diria), privilegia a velocidade da proposição dos conceitos, comparada com a profundidade dos mesmos, tanto que muitos, hoje, pensam (de uma maneira leviana) que seria suficiente pedir, unicamente, para um motor de busca (a rede internet, por exemplo) para satisfazer exigências (ou curiosidades) de matriz falsamente cultural, graças ao que os ditos motores propõem (método, porém, do qual se entrevê um primeiro crepúsculo lendo as publicações atuais). Em suma, para tais pessoas, no primeiro século do terceiro milênio, há uma grande confusão para tentar definir o que é a informação, e o que é, por outro lado, a comunicação.

(À margem gostaria de lembrar que a informação - tomando emprestado um conceito redundante - é uma notícia escolhida, enquanto a comunicação é uma primeira notícia, eu diria uma notícia sofrida. À primeira categoria aparenta responder a complexidade intrínseca de nossa disciplina, acerca da qual estamos raciocinando, em sua arquitetura de base de tradição sapiencial. À segunda remete, pelo contrário, a cultura por assim dizer popular de internet (em seu uso mais simples e primário), e aquela dos atuais (e tão disseminados) social media.

Ainda, o livro, no passar do tempo, tem se manifestado como uma entidade material - em seu aspecto exterior e interior - que encontrou uma inclusão nos repositórios bibliográficos (repertórios, guias, catálogos e bibliotecas). A forma do livro embasada na escrita, com o advento da tipografia, por muitos séculos, contribuiu para construção da linguagem intelectual. Esse tipo de linguagem torna-se um mundo, um texto. E o mundo remete o texto ao texto, assim como o texto remete à construção dos andaimes bibliográficos ou, como lembrava Spinoza, causa sive ratio, intelligere sive agere. Expressões, estas que tanto mais se procede na época atual período, mais os conceitos dentro destes pensamentos empalidecem. Seria lícito, então, nos perguntarmos quais relações poderia entreter a Bibliografia com o sistema geral e genérico de dados compartilhados e próprios das pegadas do século $\mathrm{XX}$ ? Como a própria aderiria a elas, e como, ainda, em alguns casos, agora 
poderia se separar delas, tomando um rumo que aparenta levar para um outro parterre imaginário e ideativo? (Refiro-me, de fato, à citada cultura popular dos social networks do século XXI).

Cada sociedade civil, em suas muitas exposições de natureza também antropológica e de matriz erudita (ou, pelo menos, cognitiva), ao longo de sua história contém elementos que ofereceram, em alguns casos, um impulso decisivo ao avanço das civilizações, enquanto em outras circunstâncias as mesmas tendem (talvez involuntariamente?) a deixar um espaço à sua componente barbárica. Não há dúvida de que, no século XXI, estamos perante uma avaliação complexa do que nós entendemos como disciplina bibliográfica até o final de 1900. O tempo de hoje, sabe-se, atravessou a quarta revolução da sociedade: esta revolução, que é dada pela tecnologia digital, a mesma, nos processos de transmissão da cultura livresca, expressa sua incidência que é, talvez, igual, ou superior a revolução copernicana. Ainda, esta tecnologia que lembramos, coadjuvada pela informatização dos conhecimentos compreendidos pela rede (também internet) (a qual é, porém, ainda, somente em sua primeira passagem), a necessidade exasperada de tornar visível toda ação dos comportamentos humanos (penso, por exemplo, nas inúteis fotografias (selfies...) produzidas pelos smartphones), a transformação das formas dos textos (da tipografia ao file elétrico, ao digital e-book, mas não somente esses), são todos elementos que contribuem a desenhar os estigmas dessa nova sociedade que, em sua forma primária, me parece se tornar uma espécie de sociedade visual (porque, entre outras coisas, e de passagem, é visual também a projeção dos escritos singulares nas telas dos computadores, dos tablets, etc. que, lembramos, são os meios mais utilizados pelos social media). Portanto, na base dessa trajetória, o conjunto desses instrumentos algorítmicos (incluindo os smartphones) contribui, a meu ver, a constituir uma vegetação rasteira de mensagens, de textos dos quais, provavelmente, muitos hão de revelar-se e revelam-se inúteis, e não guarnecidos de uma durabilidade própria no horizonte do saber. Assim o pensamento - entre palavra e imagem 
visual -, o existente e a ausência, o pensamento, dizia, em uma tipologia dessa natureza de sociedade visual, contém a capacidade de poder aceitar cada vez una tradição de um conhecimento intelectual, sem língua e sem voz, perante à inteligência, e à oportunidade de saber? Mas a Bibliografia, apesar disso, não está atravessando seu crepúsculo pois ela é, com certeza, e constitutivamente, Bibliografia do genitivo absoluto, isto é, memória da escrita; e a escrita - para além de sua técnica de reprodução - mesmo no tempo do digital (agora é assim, mas depois, quem sabe...) é, realmente - bem para lembrar uma banalidade - uma forma de preservação e de transmissão das ideias que residem nos vários registros textuais.

Em um meu já longínquo ensaio, escrevia: "a uma primeira abordagem a Bibliografia é aquilo que nós somos, antes de tudo e em geral: no trabalho e no tempo livre, durante o estudo e a informação, pela estrada, na existência pública e privada. A obra bibliográfica, geralmente, somos nós"s. Já faz tempo, em um semelhante leito de rio acreditou-se, e acredita-se, que o massivo desenvolvimento dos meios de comunicação (as redes, os social, com certeza) e da expansão da informática, contribuíram, e contribuem, a levar ao conhecimento dos textos de maneira imediata, através da presença das imagens, da transmissão das palavras, e da preparação de memórias elétricas. Talvez deveríamos nos perguntar se, ao lado dos méritos das novas tecnologias aplicadas à nossa disciplina, o uso excessivo da informática consentiria poder afirmar, ainda que com uma certa cautela, que está acabando a era do homem do século XX, entendido como sujeito de ciência (e de história), e está começando a era do homem enquanto objeto?

Para continuar falando ainda em termos filosóficos, entrou em crise a ambiguidade do eu penso kantiano que é, em todas as épocas, o pressuposto de um aparato qualquer para oferecer um percurso ordenado, e útil, à informação?

${ }^{5}$ CAPRONI, Attilio Mauro. L'inquietudine del sapere: scritti di teoria della Bibliografia. Milano: Edizioni Sylvestre Bonnard, 2007. p. 39. 
Além disso, nesta reflexão, para o século presente, em termos bastante pessimistas, vem o questionamento se a mecanização exasperada dos dados textuais, quando essa leva a não discernir entre o verdadeiro e o falso, a capacidade seletiva da codificação e da transmissão do saber, um contexto assim, possuiria a faculdade de configurar a imaginação do futuro? Essa, então, poderia ser configurada como reino da tecnologia tanto que, paradoxalmente, os homens - massa de hoje aspirariam à sua própria transformação em entidades mecânicas? Mas então o intelectual, principalmente de extração humanista, prever-se-ia como uma entidade desprezível que, em uma visão catastrófica do futuro, resignar-se-ia a desaparecer?

Difícil, em síntese, responder a tais questionamentos inquietantes.

Encaminhando-me, assim, rumo à conclusão, parece-me ainda poder confirmar que o século XX bibliográfico está sofrendo, como já muito destaquei, uma transformação radical no contexto da revolução digital em que as vantagens e a descrição das possíveis consequências ainda se encontram, como diriam os juristas, em um status sub judice. Permanece claro que em cada época o livro, tanto aquele tipográfico, e tanto aquele digital, o livro permanece como uma entidade absoluta. E este absoluto do livro (com os românticos, Novalis, depois, mais rigorosamente e racionalmente, com Hegel, depois mais radicalmente, mas de uma maneira diferente, com Mallarmé), tende (talvez tenderia) a afirmar-se como uma totalidade de relações em que se realizariam tanto o conhecimento que conhece a si mesma, depois de ser exteriorizada em todas as suas figuras dialeticamente apresentadas, tanto na linguagem da Bibliografia e, também, das bibliotecas. Para uma definição semelhante, então, seria necessário lembrar que, para nossa disciplina, às vezes, seria útil limitar o barulho de internet, em seu uso primário, e considerar a revolução digital da escrita um bom meio (ainda não definido, porém, em todos os seus aspectos) para atribuir aos livros, aos textos, à leitura, etc. canais de transmissão voltados a determinar, onde é possível, a profundidade e a durabilidade dos mesmos. 
Porque escrever, ler, buscar, legar, indexar são parte daquele sapere aude que Kant convidava a respeitar, de modo que todo achado da inteligência, inclusive aquele do saber escrito, possa transitar para além dos tempos contingentes.

Paris, Gênova, Roma, agosto-outubro de 2017.

\title{
REFERÊNCIAS
}

CAPRONI, Attilio Mauro. L'inquietudine del sapere: scritti di teoria della Bibliografia. Milano: Edizioni Sylvestre Bonnard, 2007. p. 39.

La Bibliografia nel XXI secolo: una riflessione. In: MISCELLANEA

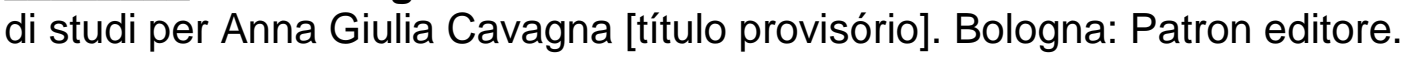

FOUCAULT, Michel. Les mots et les choses. Paris: Gallimard, 1966.

RUIZ GARCIA, Elisa. Tipologia do livro. Tradução de Diná Marques Pereira Araújo. Cadernos de História, Belo Horizonte, v. 15, n. 23, p. 208-228, out. 2014. ISSN 2237-8871. Disponível em:

<http://periodicos.pucminas.br/index.php/cadernoshistoria/article/viewFile/P.223 7-8871.2014v15n23p208/7221 >. Acesso em: 15 jun. 2018.

\section{SAPERE AUDE (SAID KANT): THE BIBLIOGRAPHY, AN ORDER OF DISCOURSE OF THE 20TH CENTURY?}

\begin{abstract}
Introduction: the historical and theoretical reflection puts in question the condition of Bibliography in the twentieth century, considered as the great century of books, from the Italian bibliographical thought. Objectives: to discuss the place of Bibliography in the twentieth century and its socio-historical determinants. Methodology: from bibliographical nature, the study was constituted as a historical work, of theoretical background, having as an argument the discourse of Kant, guided by the maxim " to have the courage to know". Results and conclusions: the reflection leads us to a discussion about the Bibliography, the book and the transformations of contemporary digital social networks, explaining the contradictions of the interpretation of such phenomena in historical time, and demarcating Bibliography as a memory of writing and the book as a kind of absolute entity.
\end{abstract}


Descriptors: Bibliography - 20th Century. Book. Knowledge. Social networks. Web.

\section{SAPERE AUDE (DECÍA KANT): LA BIBLIOGRAFÍA, UNA ORDEN DEL DISCURSO DEL SIGLO XXI?}

\section{RESUMEN}

Introducción: la reflexión histórica y teórica pone en pauta la condición de la Bibliografía en el siglo XX, considerado como el gran siglo de los libros, a partir del pensamiento bibliográfico italiano. Objetivos: discutir el lugar de la Bibliografía en el siglo XX y sus condicionantes socio-históricas. Metodología: de naturaleza bibliográfica, el estudio se constituyó como un trabajo histórico, de fondo teórico, teniendo como argumento el discurso de Kant, orientado por la máxima "tenga coraje de saber". Resultados y conclusiones: la reflexión nos conduce a la discusión sobre la Bibliografía, el libro y las transformaciones de las redes sociales digitales contemporáneas, explicitando las contradicciones de la interpretación de tales fenómenos en el tiempo histórico, y demarcando la Bibliografía como memoria de la escritura y el libro como una especie de entidad absoluta.

Descriptores: Bibliografía - Siglo 20. Libro. Saber. Redes sociales. Web.

Recebido: 10.05 .2018

Aceito: 25.08 .2018 